\title{
Localisation of two candidate genes for mental retardation using a YAC physical map of the $\mathrm{Xq} 21.1-21.2$ subbands
}

\author{
Laurence Colleaux, Melanie May, Jérome Belougne, Denis Lepaslier, \\ Charles Schwartz, Michel Fontes
}

\begin{abstract}
Genetic studies in families with $\mathrm{X}$ linked mental retardation have suggested the location of several MR genes in the human q21 region. Since the establishment of cloned resources is an essential step towards the cloning of genes involved in inherited diseases, we built a yeast artificial chromosome (YAC) contig and an STS map of this part of the $X$ chromosome. The contig, which extends from PGK1 in Xq13.3 to DXS1002 in Xq21.2, consists of 30 YACs mapped with 21 markers and spans about $6 \mathrm{Mb}$. The YAC contig was used as a framework to localise several previously known genes and CEPH/Genethon polymorphic markers, as well as to construct a physical map of the region surrounding one of these genes. We recently localised a presumed MR locus to the region flanked by DXS233 (proximal) and CHM (distal). In the present work, the zinc finger gene, $\mathrm{ZNF} 6$, has been shown to lie within this region and to be highly expressed in brain, making it a good candidate MR gene. Similarly the VDAC1 gene has been mapped between DXS986 and DXS72 and its candidate gene status for the Allan-Herndon-Dudley syndrome is discussed.

(f Med Genet 1996;33:353-357)
\end{abstract}

Key words: Xq21; mental retardation; YAC contig.

INSERM U406, Faculté de Médecine de La Timone, 27 Blvd Jean Moulin, 13385 Marseille Cedex 5, France

L Colleaux

J Belougne

$M$ Fontes

Greenwood Genetic Center, Greenwood, South Carolina, USA

$M$ May

C Schwartz

Centre d'Etude du Polymorphisme Humain, Paris, France

D Lepaslier

Correspondence to Dr Colleaux.

Received 14 November 1995 Revised version accepted for publication 9 January 1996

The dark staining band $\mathrm{Xq} 21$ is assumed to be a region in which there are few genes. However, there is strong evidence that this region may contain genes involved in brain function. For example, chromosomal rearrangements such as deletions, microduplications, or inversions of part of this chromosomal region have been reported as being associated with mental retardation. ${ }^{1-4}$ Invariably, in males with interstitial deletions of the Xq21 band, the mental retardation is associated with some other entity, usually choroideremia (CHM), but sometimes both CHM and deafness (DFN3). ${ }^{125-7}$ Other strong evidence for the presence of a gene or genes in Xq21 involved in mental retardation conditions comes from the fact that some $\mathrm{X}$ linked mental retardation (XLMR) syndromes, such as the Miles-Carpenter, ${ }^{8}$ Goldblatt, ${ }^{9} \mathrm{Cow}-$ chock-Fishbeck, ${ }^{9}$ or Allan-Herndon-Dudley syndromes, ${ }^{1011}$ as well as several non-syndromic MR entities such as MRX7, ${ }^{12} \mathrm{MRX} 8,{ }^{13}$ or MRX31, ${ }^{14}$ exhibit maximal lod scores with markers in this region. Characterisation of the deletion of Xq21 patients with overlapping phenotypes has recently allowed us to localise a gene involved in MR within the DXS233/ CHM interval. ${ }^{15}$ Using newly isolated cDNA clones to screen for mutations in patients with some forms of XLMR linked to the $2 \cdot 2 \mathrm{Mb}$ Xq13.3 region between DXS441 and PGK $1,{ }^{16}$ we have identified the XNP (X linked nuclear protein) gene as being responsible for the ATR$\mathrm{X}$ syndrome. ${ }^{17}$ Based on the success of these combined analyses, we decided to conduct physical mapping studies on the Xq21 region. Previous analyses have focused mainly on the ordering of probes using a panel of deletion or translocation patients. ${ }^{18} \mathrm{~A}$ report of PFGE experiments, conducted with some probes from the region, has been published. ${ }^{19}$ However, no cloned resources, encompassing at least part of the interval between PGK1 and DXS1002, have been described so far, neither has a complete map including physical distances. We therefore decided to cover this region with YACs and to link this new contig to our already existing YAC contig around PGK1. This was accomplished using an STS based approach to isolate MegaYACs from the CEPH library and resulted in the generation of a $6 \mathrm{Mb}$ YAC contig.

This YAC contig was then used to localise precisely several previously known genes and to build a long range restriction map of the DXS995-DXS1002 region. Our results show that the MR critical region between DXS233 and $\mathrm{pJ} 7.6 \mathrm{~A}^{15}$ is no larger than $1.2 \mathrm{Mb}$ and that the zinc finger gene ZNF6 lies within this region. We also identified, within the same $M R$ critical region, a new potential $\mathrm{CpG}$ island which might be indicative of at least a second transcription unit within this MR critical region. Moreover, the resources we have produced allowed us to localise another previously known gene, the VDAC1 gene, ${ }^{20}$ between DXS986 and DXS72. This result, in combination with the potential function of the VDAC1 protein, makes the VDAC1 gene a good candidate for being involved in the AllanHerndon-Dudley syndrome. 
Table 1 Previously unpublished STSs used to construct the contig

\begin{tabular}{|c|c|c|c|c|}
\hline Name & Probe & Primer sequence & $\begin{array}{l}\text { Product } \\
\text { size }(b p)\end{array}$ & Timp \\
\hline DXS571 & pHX79 & $\begin{array}{l}\text { AATATTGGTGCAGGCACTGT } \\
\text { AATCAGATGCAGTGATGGGT }\end{array}$ & 129 & $55 \mathrm{C}$ \\
\hline DXS447 & & $\begin{array}{l}\text { TCCACACCGACT TGTATTGC } \\
\text { TTTACCAGCTGGATGAGGC }\end{array}$ & 226 & $57 \mathrm{C}$ \\
\hline VDAC 1 & $\mathrm{cDNA}$ & $\begin{array}{l}\text { TGAACAAGAAGT TGGAGACCG } \\
\text { TTCTTGCCATCCAGAAGAGC }\end{array}$ & 208 & $60 \mathrm{C}$ \\
\hline DXS72 & $\mathrm{pX} 65 \mathrm{H} 7$ & $\begin{array}{l}\text { CAATTTTCTGCCAATTAGGATC } \\
\text { GTAGTTGACTTCGAGCTGGC }\end{array}$ & 221 & $55 \mathrm{C}$ \\
\hline ZNF6 & $5^{\prime} \mathrm{cDNA}$ & $\begin{array}{l}\text { ACTCTTGATCATGGCCTTGC } \\
\text { CAGTAACAAGGTCAGCCACG }\end{array}$ & 228 & $56 \mathrm{C}$ \\
\hline & $3^{\prime}$ cDNA & $\begin{array}{l}\text { AGCATITGGTGATGAGAGGG } \\
\text { CCTGCACGTATGAATCTTCCIAC }\end{array}$ & 244 & $56^{\circ} \mathrm{C}$ \\
\hline $\mathrm{CHM}$ & $\mathrm{cDNA}$ & $\begin{array}{l}\text { CACCAAACTGGATACCCA } \\
\text { TGAGCAAGTCAATGTGC'T }\end{array}$ & 237 & $65 \mathrm{C}$ \\
\hline
\end{tabular}

The primer sequences are given in a $5^{\prime}$ to $3^{\prime}$ orientation. When the primers derive from a previously published probe, the name of the corresponding probe is indicated. CDNA: primer design according to the cDNA sequence corresponding to the gene.

\section{Methods}

YAC LIBRARY SCREENING

Pools of the CEPH MegaYAC library were screened by PCR for the presence of DXS571, DXS447, and DXS72 using the primers and the annealing conditions shown in table 1. Screening for locus DXS326 was carried out using the primers described in Barker and Fain. ${ }^{21}$ The PCR conditions were $96^{\circ} \mathrm{C}$ for 30 seconds, one minute at the annealing temperature, and $72^{\circ} \mathrm{C}$ for 40 seconds for 40 cycles.

LONG RANGE RESTRICTION MAPPING

YAC DNA embedded in agarose was digested to completion with either $S f i \mathrm{I}, N o t \mathrm{I}, M l u \mathrm{I}$, or EagI using the buffer supplied by the manu- facturer (New England Biolabs). The fragments were then electrophoresed on a $1 \%$ agarose (Gibco BRL) gel in a CHEF DRII PFGE apparatus (Biorad) using switch times from 40 seconds to 120 seconds at $200 \mathrm{~V}$ for 30 to 38 hours in $0.25 \times \mathrm{TBE}$ at $12^{\circ} \mathrm{C}$. The DNA was then transferred to nylon Biodyne membranes (Pall Industries).

\section{PROBE PREPARATION AND HYBRIDISATION} CONDITIONS

Probes were labelled using the random priming procedure as previously described. ${ }^{22}$ Southern blot hybridisations were carried out in a standard SSC buffer $(5 \times$ SSC, $5 \times$ Denhardt's, and $0.1 \%$ SDS) for 16 to 18 hours at $65^{\circ} \mathrm{C}$ in a rotary hybridisation oven. Washes were performed as follows: 20 minutes in $2 \times \mathrm{SSC} / 0 \cdot 1 \%$ SDS, 20 minutes in $0.5 \times \mathrm{SSC} / 0 \cdot 1 \% \mathrm{SDS}$, and five to 20 minutes in $0.1 \times \mathrm{SSC} / 0 \cdot 1 \% \mathrm{SDS}$ according to the stringency of the washes. A Northern blot filter was purchased from Clontech and hybridised according to the manufacturer's recommendation. All membranes were exposed to X-OMAT AR film (KODAK) from one hour to five days.

\section{Results}

ISOLATION OF YAC CLONES AND CONTIG CONSTRUCTION

As a preliminary step towards the construction of a YAC contig encompassing the $\mathrm{Xq} 21$ re-

Table 2 STSs and probe content of YACs between PGK1 and DXS1002

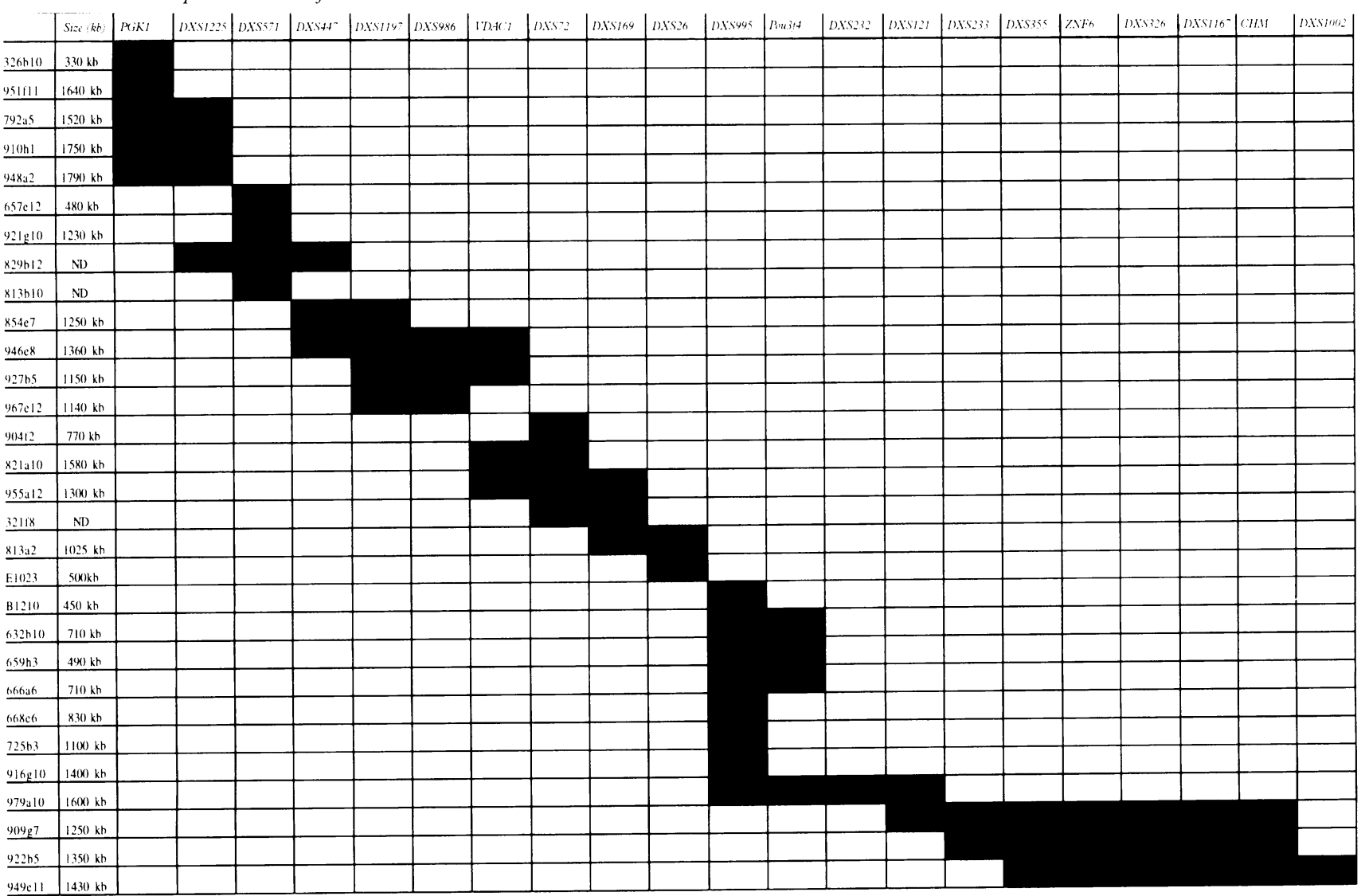

The upper line indicates the STS/probe markers used to build the YAC contig and their order as it appears on the contig map (fig 1). The size of the YACs has been determined according to the CEPH-GENETHON database or in this study. ND: not determined 


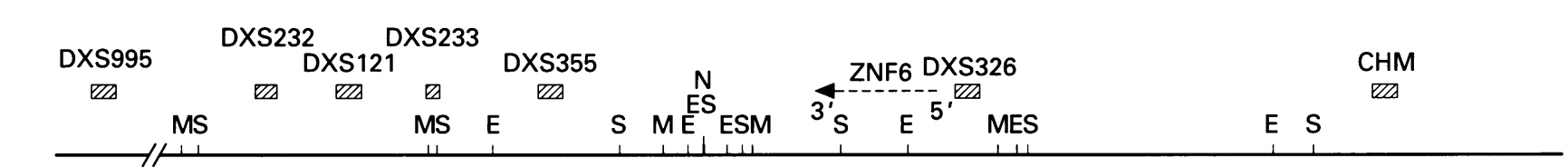

$979 A 10---1 / \longrightarrow$

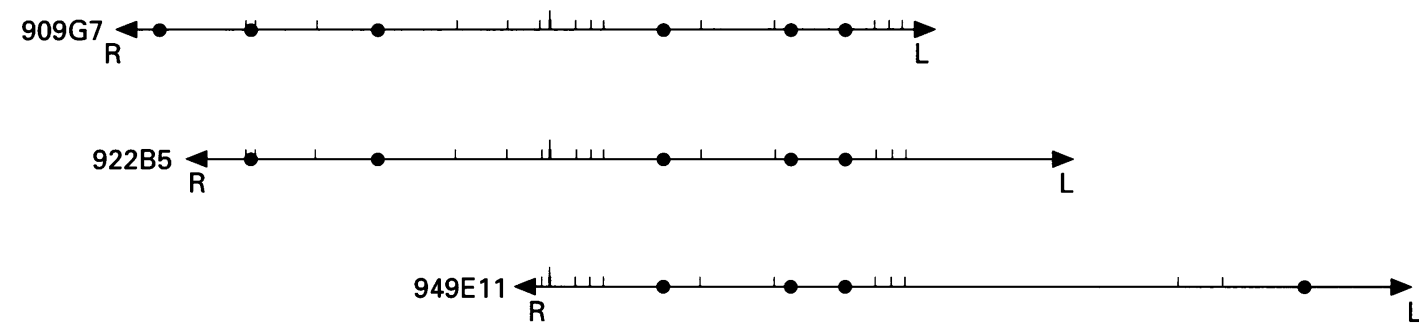

Figure 1 Long range restriction map of the DXS232-CHM region. Location of the Xq21 reference loci is indicated by hatched boxes. Restriction sites are $E=E a g I, M=$ MluI, $N=$ NotI, and $S=$ SfiI. Filled circles represent the $Y A C$ restriction fragment hybridising with the probe indicated above. The probe DXS326 and the probe corresponding to the $5^{\prime}$ end of the ZNF6 gene have been arbitrarily ordered as our results do not allow ordering of one with respect to the other.

gion, the CEPH MegaYACs library was screened for the loci DXS571, DXS447, DXS72, and DXS326. Three DXS571 positive YACs (813b10, 829b12, 921g10), two DXS447 positive YACs $(854 \mathrm{e} 7,967 \mathrm{e} 12)$, three DXS72 positive YACs $(767 \mathrm{e} 4,821 \mathrm{a} 10,321 \mathrm{f} 8)$, and three DXS326 positive YACs (909g7, $922 \mathrm{~b} 5,949 \mathrm{e} 11$ ) were characterised at this stage. The CEPH-Genethon database ${ }^{23}$ was then used to identify YACs that either mapped to the region on the basis of their STS contents (six YACs positive for DXS995 (632b10, 659h3, 666a6, 668e6, 725b3, and 894c7), one additional YAC positive for DXS571 $(657 \mathrm{e} 12)$, one YAC positive for DXS1225 (910h1), and two YACs positive for DXS986 (946e8, 927b5)) or appeared to contig with YACs that had already been placed in the contig (951f11, $792 \mathrm{a} 5,948 \mathrm{a} 2$ that were in contig with $910 \mathrm{~h} 1$ and $749 \mathrm{~h} 4,955 \mathrm{a} 12,904 \mathrm{f} 2,838 \mathrm{c} 5$ that were in contig with 821a10). In total, $28 \mathrm{CEPH}$ MegaYACs were further studied with 21 markers including five genes.

The individual STS or probe content of each YAC was then determined by the combined use of PCR and hybridisation. In addition to the previously published original set of STSs from this region, several additional ones were developed. They are listed in table 1 and the STS data are summarised in table 2 . This led to the assembly of two contigs spanning from PGK1 to DXS26 and from DXS995 to DXS1002. Since an $850 \mathrm{~kb}$ YAC and cosmid contig encompassing the DFN3 locus and linking the two loci DXS26 and DXS995 had previously been described, ${ }^{24}$ two additional YACs from the ICRF library, ICRFy901E1023 and ICRFy900B1210 respectively, were also studied and included in the final unique contig.
RESTRICTION MAPPING OF THE MR CRITICAI REGION AND ESTIMATION OF THE CONTIG SIZE As described in the introduction, we previously localised the proximal and distal borders of the candidate region for one $\mathrm{MR}$ gene in $\mathrm{Xq} 21$ between DXS233 and CHM respectively. ${ }^{15} \mathrm{We}$ therefore decided to construct a restriction map of this region to order closely spaced markers and estimate the true distances between loci. Mapping was conducted using the four rare cutter endonucleases $S f i \mathrm{I}, M l u \mathrm{I}$, NotI, and EagI and the YACs 979a10, 909g7, 922b5, and $949 \mathrm{e} 11$. The map was assembled using probes derived from the left and right ends of the pYAC4 vector, as well as internal probes corresponding to STSs or genes. Eventually, membranes were hybridised with total human DNA to ensure that all restriction fragments had been detected. The result is shown in fig 1 . Using this map, it was possible to order a number of markers from the region. From the centromere to the telomere, the following order was found: DXS232-DXS121-DXS233-DXS355(DXS326, DXS1167, ZNF6)-CHMDXS1002-DXS95. This is in agreement with data previously obtained by other groups. ${ }^{1825}$ Analysis of the rare cutter restriction map of the region showed at least one cluster of sites containing a NotI site, which could correspond to a $\mathrm{CpG}$ island, approximately $400 \mathrm{~kb}$ distal to DXS233, between DXS355 and DXS326.

Previous studies ${ }^{26}$ have shown that the human ZNF6 gene is localised between DXS233 and CHM. A probe specific for the $5^{\prime}$ end of the cDNA, hybridised to a $300 \mathrm{~kb}$ $S f i$ fragment, a $400 \mathrm{~kb} M l u I$ fragment, and a $200 \mathrm{~kb}$ EagI fragment, positioning that end of the gene approximately $800 \mathrm{~kb}$ distal to DXS233. A probe corresponding to the $3^{\prime}$ end 


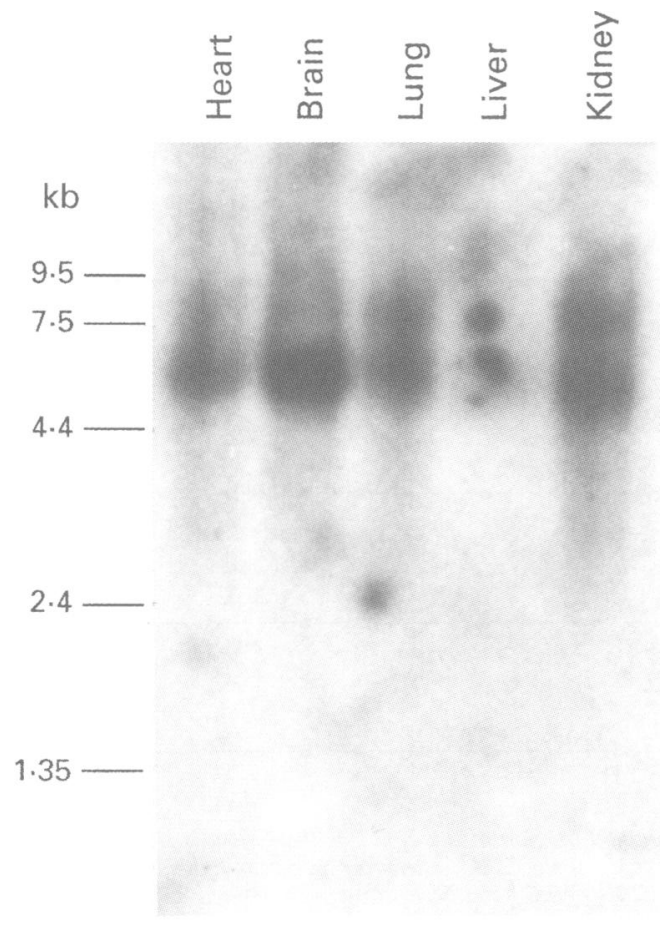

$\beta$-actin probe

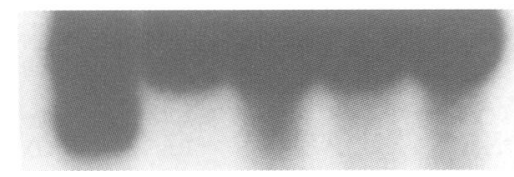

Figure 2 Expression analysis of the ZNF6 gene. A human multiple fetal tissue northern blot (Clontech) was hybridised with a probe corresponding to the ZNF6 gene. The probe identifies a $5.5 \mathrm{~kb}$ transcript highly expressed in brain, less abundantly in heart, lung, and kidney, and almost undetectable in liver. The same blot was also hybridised with the actin probe to determine the relative quantities of RNA loaded per lane.

of the gene hybridised to a $200 \mathrm{~kb} S f i$ fragment and a $350 \mathrm{~kb}$ EagI fragment. According to the map (fig 1), this result indicates that the $5^{\prime}$ specific probe hybridises to a fragment distal to the one hybridised by the $3^{\prime}$ end, thereby establishing that ZNF6 is transcribed telomere to centromere and is localised between DXS355 and DXS326.

Recent studies have mapped the human gene encoding the mitochondrial voltage dependent anion channel gene, VDAC $1,{ }^{20}$ into the Xq13q21 interval. We therefore decided to localise this gene precisely on the YAC contig by PCR amplification to associated STSs. The results show that it lies between DXS986 and DXS72. Similarly to what we did for the ZNF6 gene, the use of specific $5^{\prime}$ end or $3^{\prime}$ end specific probes and preliminary data on the physical map of the region surrounding the VDAC1 gene allowed us to determine that it is orientated from the telomere to the centromere.

Finally, to approximate the size of the contig we combined the chimerism/size data determined either by ourselves or through the CEPH-Genethon database. The three nonoverlapping, non-chimeric YACs, 946e8, $813 \mathrm{a} 2$, and $949 \mathrm{e} 11$, give a minimum size of approximately $3.8 \mathrm{Mb}$ between DXS447 and DXS1002. According to our long range restriction maps, the minimum distances between DXS995-DXS355 and between VDAC1DXS169 are about $1 \mathrm{Mb}$ and $400 \mathrm{~kb}$ respectively. The size of the most proximal YACs (326b10, 910h1, 657e12) and their chimerism status according to the CEPH databases suggest that the distance between PGK1 and DXS447 should be about $600 \mathrm{~kb}$. Finally, a previous publication reported the distance between DXS26 and DXS995 to be $250 \mathrm{~kb}^{24}$ Therefore, considering all these data, we estimate the size of our contig to be about $6 \mathrm{Mb}$ from PGK1 to DXS1002.

EXPRESSION STUDIES OF THE ZNF6 GENE

Since the ZNF6 gene, which maps between DXS233 and CHM, encodes for a putative zinc finger transcriptional factor, its position and putative function led us to speculate that a deficiency in the expression of such a gene could be involved in a form of mental retardation. In order to study its candidate gene status, we performed a northern blot experiment, using RNAs extracted from a variety of fetal tissues (fig 2). A $5.5 \mathrm{~kb}$ transcript was identified and showed that the ZNF6 gene is highly expressed in fetal brain with lower expression in heart, kidney, and lung and very low expression in liver. In addition to this $5.5 \mathrm{~kb}$ transcript, a larger one, about $7.5 \mathrm{~kb}$, was also identified in kidney and lung. Whether this larger fragment corresponds to an alternatively spliced transcript remains to be determined; however, our finding that the ZNF6 gene is highly expressed in brain makes it a good candidate for being involved in the MR syndrome.

\section{Discussion}

The present work describes the generation of a $6 \mathrm{Mb}$ YAC contig spanning the genomic region between PGK1 in Xq13.3 and DXS1002 in $\mathrm{Xq} 21.2$. When we started this work, a small YAC contig linking DXS26 and DXS995 had been described, ${ }^{24}$ and pulse field electrophoresis analysis of genomic DNA had shown the close proximity of loci DXS232, DXS121, and DXS233. ${ }^{\circ}$ However, despite these data, the region running from DXS447 to DXS1002 was split into many contigs and several probes or STSs, such as DXS326, DXS355, or ZNF6, were not included in any contig. ${ }^{25}$ The contig we have built contains 30 YACs and 21 STSs have been ordered within this contig. Because the STS order we deduced from our YAC contig is consistent with the ordering of probes resulting from the use of a panel of deletion or translocation patients, ${ }^{18}$ we think that these YACs are representative of the corresponding genomic region and should provide useful cloned resources for further analysis.

Since our previous results concerning the molecular analysis of males with mental retardation and deletions of $\mathrm{Xq} 21$ placed the putative MR region between DXS233 and $\mathrm{CHM},{ }^{15}$ we built a long range restriction map of the DXS232 to DXS1002 interval. It shows 
that the critical region for the MR gene, between DXS233 and pJ7.6A, is about $1.2 \mathrm{Mb}$. Interestingly, our physical map is in good agreement with the data obtained by Merry et al ${ }^{1}$ on the long range restriction map of the genomic region containing DXS232 and DXS233, suggesting that these YACs are fully representative of the genomic region analysed. Two candidate MR genes, based upon their chromosomal localisation, have already been characterised. The first one, the ZNF6 gene, codes for a zinc finger transcriptional factor and is localised between markers DXS355 and DXS326. Our study on patients with contiguous deletion syndromes show that it is localised within the MR critical region, ${ }^{15}$ being deleted in all patients with MR associated with CHM only or with CHM and deafness, but present in two patients with only CHM. Its candidate gene status is strongly supported by the results of northern blot experiments which showed high expression in fetal brain. We also characterised a potential new $\mathrm{CpG}$ island within this critical region. Since the construction of the physical map of this region has allowed us to orientate the ZNF6 gene as cen-3'-ZNF6-5'-tel, this new $\mathrm{CpG}$ island could possibly be an island indicative of a new transcription unit. cDNA selection experiments are at present being performed to try to isolate this new gene.

The second candidate gene, VDAC 1 , is localised close to DXS72. Since recent findings have shown that abnormalities in genes encoding these channels cause a number of neurological disorders in mice ${ }^{27}$ and men, ${ }^{28}$ the VDAC1 gene may well be involved in neuromuscular disorders, most notably the AllanHerndon-Dudley syndrome. Indeed, this syndrome, which is characterised by severe mental retardation and spastic paraplegia, has been localised within DXS571 and DXS326 with a lod score of about 7 (Schwartz et al, in preparation). Furthermore, among the numerous male viable deletions spanning almost the entire Xq21 region studied, most are only associated with a mild MR condition. Only patients deleted proximal to DXS72 exhibit severe mental retardation. ${ }^{6}$ Thus, one could speculate that the AHD gene is very likely localised upstream of this locus, between DXS571 and DXS72, making the VDAC1 gene a very good candidate gene for the AllanHerndon-Dudley syndrome. As illustrated by the recent finding, resulting from the combination of positional cloning and candidate gene approaches, that the POU domain gene BRN4 is implicated in $\mathrm{X}$ linked mixed deafness, ${ }^{29}$ the physical map reported here should greatly facilitate the identification of genes involved in XLMR as well as other genetic diseases assigned to this part of the chromosome. Using the YAC clones described here, work is now under way to create an extensive transcriptional map of the Xq21 region.

LC, JB, and MF were supported by a grant from the Association Française contre les Myopaties (AFM). MM and CS were supported, in part, by a grant from the South Carolina Department of Disabilities and Special Needs and a grant from NICHD.
1 Merry DE, Leslo JG, Sosnoski DM, et al. Choroideremia and deafness with stapes fixation: a contigous gene deletion syndrome in Xq21. Am 7 Hum Genet 1989;45:530-40.

2 Schwartz M, Rosenberg T, Niebuhr E, et al. Choroideremia: further evidence for assignment of the locus to Xq13$\mathrm{Xq} 21$. Hum Genet 1986;74:449-52.

3 Abeliovitch D, Dagan J, Kimchi-Sarfati C, Zlotogora J. Paracentric inversion X(q21.2q24) associated with mental retardation in males and normal ovarian function in females. Am f Med Genet 1995;55:359-62.

4 Yokoyama Y, Narahara K, Tsuji K, et al. Growth hormone deficiency and empty sella syndrome in a boy with $\operatorname{dup}(\mathrm{X})(\mathrm{q} 13.3-\mathrm{q} 21.2)$. Am f Med Genet 1992:42:660-4

5 Nussbaum RI Leso JG, Lewis RA, Ledbetter SA, Led better $\mathrm{DH}$. Isolation of anonymous sequences from within better $\mathrm{DH}$. Isolation of anonymous sequences from within a submicroscopic $\mathrm{X}$-chromosome deletion in a patient with choroideremia, deafness and me

6 Cremers FPM, van de Pol DJR, Diergaarde PJ, et al. Physical mapping of the choroideremia locus using Xq21 deletions associated with complex syndromes. Genomics 1989;4: $41-6$

7 Hodgson SV, Robertson ME, Fear CN, et al. Prenatal diagnosis of $\mathrm{X}$-linked choroideremia with mental retardation, associated with a cytologically detected X-chromosome deletion. Hum Genet 1987;75:286-90.

8 Carpenter NJ, Waziri M, Liston J, Patil SR. Studies on Xlinked mental retardation: evidence for a gene in the region Xq11-q22. Am f Hum Genet 1988;43:A139.

9 Neri G, Chiurazzi P, Arena JF, Lubs HA. XLMR genes: update 1994. Am $\mathcal{F}$ Med Genet 1994;51:542-9.

10 Schwartz CE, Ulmer J, Brown A, Pancoast I, Goodman HO, Stevenson RE. Allan-Herndon syndrome. II. Linkage to DNA marker in Xq21. Am $\mathcal{f}$ Hum Genet 1990;47: to D $4-8$.

11 Schwartz CE, Martin J, Ouzts L, Arena JF, Lubs AH, Stevenson RE. Allan-Herndon-Dudley syndrome, linkage analysis in a third family and refinement of the localization in Xq21. Cytogenet Cell Genet 1994;67:351.

12 Jedele KB, Michels VV, Wagner KV. Linkage analysis demonstrating association of DXYS 1 and nonspecific X-linked mental retardation. Am $\mathcal{F}$ Hum Genet 1990;47:A62.

13 Schwartz CE, May M, Huang T, et al. MRX8: an X-linked mental retardation condition with linkage to $\mathrm{Xq} 21 . A m \mathcal{F}$ Med Genet 1992;43:467-74

14 Partington MW, Ryan A, Donnelly AJ, Mulley JC. Two families with X-linked mental retardation (XLMR) from Queensland. Am 7 Med Genet (in press)

15 May M, Colleaux L, Murgia A, et al. Molecular analysis of four males with mental retardation and deletions of Xq21 places the putative MR region in Xq21.1 between DXS233 places the putative MR region in Xq21.1 betwe
and CHM. Hum Mol Genet 1995;4:1465-6.

16 Villard L, Gecz J, Colleaux L, et al. Construction of a YAC contig spanning the Xq13.3 subband. Genomics 1995;26: $115-22$.

17 Gibbons RJ, Picketts DJ, Villard L, Higgs DR. Mutations in a putative global transcriptional regulator causes $\mathrm{X}$ linked mental retardation with $x$-thalassemia (ATR-X syndrome). Cell 1995;80:837-45.

18 Philippe C, Arnould C, Sloan F, et al. A high-resolution interval map of the q21 region of the human X chromosome. Genomics 1995;27:539-43.

19 Cremers FPM, Sankila EM, Brunsmann F, et al. Deletions in patients with classical choroideremia vary in size from in patients with classical choroideremia vary in size from $62 \mathrm{~kb}$ to

20 Blachly-Dyson E, Baldini A, Litt M, McCabe ER, Forte $M$. Human genes encoding the voltage-dependent anion channel (VDAC) of the outer mitochondrial membrane: mapping and identification of two new isoforms. Genomics 1994;20:62-7.

21 Barker DF, Fain PR. Definition and mapping of STSs at STR and RFLP loci in Xp11-Xq22. Genomics 1993;18: 712-16.

22 Feinberg AP, Vogelstein B. A technique for radiolabelling DNA restriction endonuclease fragments to high specific activity. Anal Biochem 1984;137:266-7.

23 Cohen D, Chumakov I, Weissenbach J. A first generation physical map of the human genome. Nature 1993;366: 698-701.

24 Huber I, Bitner-Glindzicz M, de Kok YJM, et al. X-linked mixed deafness (DFN3): cloning and characterization of mixed deafness (DFN3): cloning and characterization of the critical region allows identification of
crodeletions. Hum Mol Genet 1994;3:1151-4.

25 Willard HF, Cremers F, Mandel JL, Monaco AP, Nelson $\mathrm{DL}$, Schlessinger D. Report of the fifth internationa workshop on human $\mathrm{X}$ chromosome mapping 1994. Cytogenet Cell Genet 1994;67:295-358.

26 Lloyd SL, Sargent CA, Chalmers J, Lim E, Habeebu SSM Affara NA. An X-linked zinc finger gene mapping to $\mathrm{Xq} 21.1-\mathrm{q} 21.3$ closely related to ZFX and ZFY: possible origins from common ancestral gene. Nucleic Acids Res 1991;19:4835-41.

27 Nakatsu Y, Tindale RF, DeLorey TM, et al. A cluster of three $\mathrm{GABA}_{\mathrm{A}}$ receptor subunit genes is deleted in a neurological mutant of the mouse $p$ locus. Nature 1993; 364:448-50.

28 Shiang R, Ryan SG, Zhu YZ, Hahn AF, O'Connell $\mathrm{P}$, Wasmuth JJ. Mutations in the $\boldsymbol{x}_{1}$ subunit of the inhibitory glycine receptor cause the dominant neurological disorder glycine receptor cause the dominant neurolo

29 de Kok YJM, van der Maarel S, Bitner-Glindzicz M, et al. Association between X-linked mixed deafness and mutations in the POU domain gene POU3F4. Science 